\title{
The choice of Bass model coefficients to forecast diffusion for innovative products: An empirical investigation for new automotive technologies
}

\author{
Authors : Jérôme MASSIANI ${ }^{1}$, Andreas GOHS ${ }^{2}$ \\ 1- Università Cà Foscari di Venezia, Dipartimento di economía, Cannaregio 873, 30121 \\ Venezia, j.massiani@unive.it
}

2- Kassel Universität

Provisory release. Final version published on Research in Transportation Economics. With DOI: doi:10.1016/j.retrec.2015.06.003

\section{Abstract}

Bass diffusion models are one of the competing paradigms to forecast the diffusion of innovative products or technologies. This approach posits that diffusion patterns can be modeled through two mechanisms: Innovators adopt the new product and imitators purchase the new product when getting in contact with existing users. Crucial for the implementation of the method are the values assigned to the two parameters, usually referred to as $\mathrm{p}$ and $\mathrm{q}$, which mathematically describe innovation and imitation mechanisms. The present paper is based on the findings of a research project about policy measures to promote the diffusion of Electric Vehicles in Germany. It investigates how practitioners could choose adequate values for the Bass model parameters to forecast new automotive technologies diffusion with a focus on Electric Vehicles. It considers parameters provided by the literature as well as ad hoc parameter estimations based on real market data for Germany. Our investigation suggests that researchers may be in trouble in electing adequate parameter values since the different eligible parameter values exhibit dramatic variations. Literature values appear discussible and widely variable while ad hoc estimates appear poorly conclusive. A serious problem is that ad-hoc estimates of the Bass $p$ value are highly sensitive to the assumed market potential $M$. So for plausible values of $M, p$ varies on a high scale. Unless more consolidation takes place in this area, or more confidence can be placed on ad hoc estimates, these findings issue a warning for the users of such approaches and on the policy recommendations that would derive from their use.

Keywords: bass diffusion model, innovation, electric vehicles

JEL : Q55, 033 


\section{Introduction}

With the increasing popularity of Electric Vehicles (EVs) among policy makers and the general public, economists have been called to design convincing methods for forecasting the development of this market. Among the various competing paradigms, Bass diffusion theory received attention from scientists and has been applied in research projects as is reported in a number of scientific communications. Yet approaches based on the diffusion model $a$ la Bass still lack a form of consolidation in that, to our knowledge, no effort has been made, at least in our field, to compare the underlying parameters in a systematic manner and to assess how analysts can select parameter values to conjecture market diffusion scenarios. These parameters known as $p$ and $q$, or coefficients for innovation and imitation represent the intrinsic driving forces, together with potential $M$, of the diffusion pattern of the innovative technology, and thus deserve careful consideration.

This paper aims at filling in this gap, as it provides a systematic examination of the $p$ and $q$ parameters proposed in the literature as well as parameter estimates based on real market data. Based on extensive research and state of the art analysis performed during a research project about policy measures to promote the diffusion of Electric Vehicles in Germany, our initial intention was to provide guidelines for practitioners in their choice of parameter values for EV diffusion forecast. However, our findings raise skepticism on the possibility to convincingly model EV market diffusion through the Bass model, considering the dramatic discrepancy between reported estimates and the inconclusiveness of ad hoc estimates.

The paper proceeds as follows: In the next section, the Bass model for innovation diffusion is presented. The third section investigates the estimates provided by literature about the value of $p$ and $q$ parameters for innovative automotive technologies. The fourth section presents the results of our own estimations based on real market data collected for the German market. The conclusion puts into perspective these different results and underlines the difficulty which researchers and practitioners may encounter when electing the Bass parameter values.

\section{The Bass model of diffusion}

Electric Vehicles (EVs), Hybrid Electric Vehicles (HEVs), Biofuel Vehicles and, to some extent, Liquid Petroleum Gas (LPG) and Compressed Natural Gas (CNG) propelled vehicles can be considered as new propulsion technologies which could potentially substitute established Internal Combustion Engine technologies (i.e. Gasoline and Diesel powered vehicles). The adoption of new technologies has often been found to follow an S-shaped curve. In this setting, cumulated purchases of innovative products can be characterised by three different growth phases: a slow take-up phase, followed by a phase of more rapid growth as the technology becomes widespread and, finally, slowing growth when the 'not so new' technology approaches saturation. Diffusion theories try to explain or model the actual shape of diffusion curves - i.e. the speed and the shape of cumulative adoption of an innovation among a set of prospective buyers. A widely used approach in marketing to explain the diffusion of innovations is the so-called Bass model (Bass 1969).

\subsection{Bass model in synthesis}

The Bass model assumes that potential buyers of an innovation can be divided into two groups:

- Innovators: People who buy the product first and are influenced only by 'external communication' e.g. mass media or advertisement. 
- Imitators: Individuals who, in contrast, buy if others have already bought the product since they are influenced by word of mouth or so-called 'internal communication' (Mahajan, Muller et al. 1990).

Following this narrative, the number of first time purchases $n_{t}$ at time $t$ can be expressed as follows:

$$
n_{t}=\frac{d N_{t}}{d t}=p\left(M-N_{t}\right)+q \frac{1}{M} N_{t}\left(M-N_{t}\right)
$$

With:

$\mathrm{n}_{\mathrm{t}}$ : product purchases in period $\mathrm{t}$

$\mathrm{N}_{\mathrm{t}}$ : cumulative product purchases until beginning of period $\mathrm{t}$

$M$ : cumulative market potential on the whole product's life cycle

$p$ : coefficient of innovation

$q$ : coefficient of imitation.

Alternatively, the model is sometimes written as (this may turn out useful looking at some authors who use this notation):

$$
f(t)=(p+q F(t))(1-F(t))
$$

With

$f(t)$, density function of sales at time $t$,

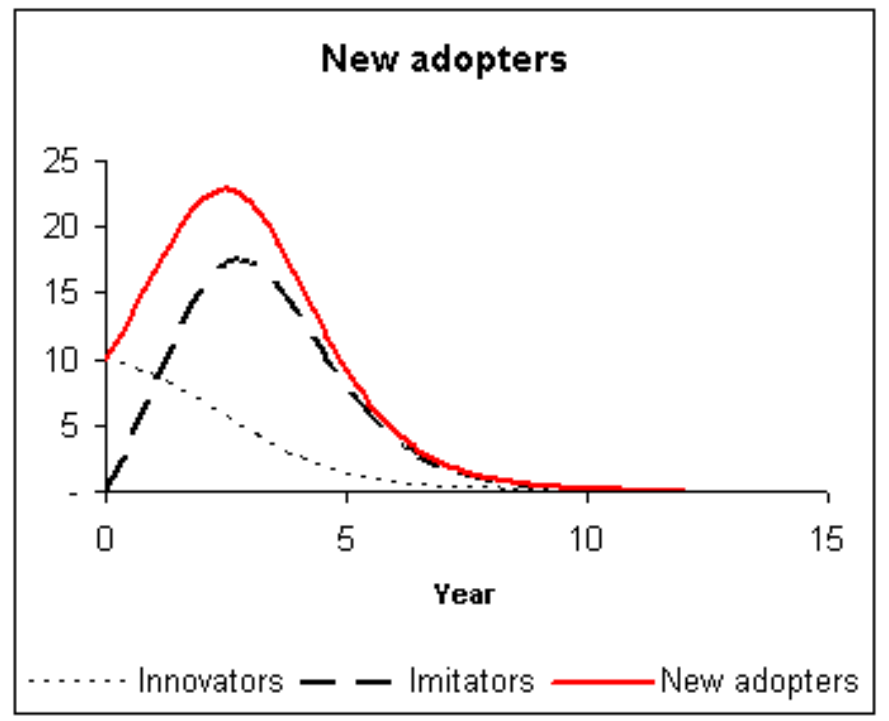

$F(t)$, cumulative fraction of the potential that is achieved at time $t$.

Figure 1 - a typical textbook illustration of diffusion patterns in the Bass model

Integrating over time, the total fraction of the potential that is adopted at time $t$ is:

$$
F(t)=\frac{1-e^{-(p+q) t}}{1+\frac{p}{q} e^{-(p+q) t}}
$$


These premises set, it is all apparent that the diffusion pattern will be highly dependent of the following elements:

- The estimate of the potential market,

- The values used for $\mathrm{p}$ and $\mathrm{q}$.

Armoured with this apparatus, the Bass model has become a leading paradigm for the forecast of innovative technology diffusion. In the subsequent section, we analyse more in detail the reasons for such a success.

\subsection{The Bass model: A long lasting success}

The Bass model is routinely used by analysts to explore the market potential for innovative propulsion technologies. The Bass model is often applied in studies where diffusion plays a decisive or critical role. For example, diffusion assumptions are key drivers in energy studies like that of (Lee, Park et al. 2013), but are considered with limited attention in this field of research, because the main focus is often on energy generation and distribution issues.

This success relates to different factors. First, the model is authoritative, especially in management sciences. Bass seminal paper was selected in 2004 as one of the ten most frequently cited papers in the 50 -year history of Management Science ${ }^{1}$. The rhetoric of Bass approach also insists on the initial success of the model: The diffusion patterns predicted by Bass in his original 1969 article have shown to adhere convincingly with subsequent real market outcomes for the set of technologies considered by the author. Massiani (2012) also analyses other reasons of success of the Bass paradigm in comparison with other competing approaches to model the diffusion of Alternative Propulsion Technologies: Bass diffusion patterns have a good face value as they draw a smooth diffusion curve, which is consistent with the common perception of a slow uptake and a saturation when demand becomes higher. Additionally, those diffusion patterns are intrinsically made consistent with the time series observed up to the present time. Additionally, Bass models are data parsimonious: A time series of the seminal diffusion of a given technology is usually the only requirement to estimate Bass parameters. Also an analyst can rely on preexisting estimates of the set of $\mathrm{p}, \mathrm{q}$ and $\mathrm{m}$ parameters. Compared to Stated Preference (or Conjoint Analysis) surveys, that usually require collections of specific data (except in the proposed Synthetic Utility Function advocated in Massiani, 2012) and more elaborated computations, and to Total Cost of Ownership that necessitates a large set of engineering and accounting data, the Bass approach can constitute an attractive alternative. Bass, Krishnan et al. (1994) also show that the Bass model fits sales almost as well as much more complex models that seek to correct its limitations (Chandrasekaran and Tellis 2007). Consistently with these results, the simple Bass model still dominates other approaches in many areas of application, and its parsimony and good face value could durably foster its success.

Counteracting to these advantages, the main critics formulated to the Bass approach are related to the absence in the model of other explanatory variables like prices or advertising efforts. This gave rise to the Generalised Bass model which was shown, under fairly general assumptions, to collapse to the simple Bass model. Other critics relate to the lack of micro foundation of the model: Actually the model contains

\footnotetext{
${ }^{1}$ Management Science 50 Number 12 Supplement, Dec 2004 ISSN 0025-1909 p1833-1840
} 
no positive description of how individuals behave. The assumption about innovators and imitators provides only limited insights into the mechanisms of the choice processes of individuals. Additionally, it remains unclear whether innovativeness and imitativeness are a priori features of an individual (potentially defined in relation to the good at hand) or are a posteriori clusterings of individuals based on observed behavior (explained by more complex mechanisms). In this latest assumption, it would be the exploration of these more profound mechanisms (and we touch here the realm of consumer psychology) that would be of ultimate interest for the understanding and forecast of market diffusion. In other words, the Bass model may describe diffusion processes, but it may not explain them. But eventually it is this explanation that would be necessary to grant the approach sufficient realism and versatility.

\subsection{The critical role of Bass parameters}

In a context where the Bass model has become very influential, it is important that sufficient confidence can be obtained in the realism of the various parameters that ultimately drive the outcome of the method. There are first some issues related to the estimate of $M$, see (Massiani 2012). In circumstances where, instead, the analyst can rely on sound estimates of the market potential (this can be for instance provided by the application of a discrete choice model as in Massiani (2015)), analysts can focus on the values to choose for $\mathrm{p}$ and $\mathrm{q}$. While the literature proposes a number of assumptions or estimates for these values, to the best of our knowledge, no critical review seems available that investigates how and whether practitioners may find a practical solution to the problem of a proper choice of $\mathrm{p}$ and $\mathrm{q}$. For research about the diffusion of new automotive technologies, it appears useful for us, to analyse available information about the adequate values for $p$ and $q$ considering two sources: A literature review, and an estimation on a data set of new automotive technologies, essentially in Germany.

\section{Literature review: widely variable values are available for Bass parameters}

This section reviews the values of $p$ and q parameters found in literature sources. Several types of sources can be distinguished based on whether they refer to other (partly authoritative) sources or whether they produce an own estimate.

\subsection{Reference to authoritative sources}

First, part of the literature provides interval rather than point values for $p$ and $q$ coefficients. In a review of the Bass literature, Chandrasekaran and Tellis (2007) refer to $p$ values between 0.00007 and 0.03 with higher values for Europe than for the U.S. (Sultan, Farley et al. 1990). Values for the parameter q would be in the interval from 0.38 to 0.53 . However, these intervals are too large to provide a useful guidance to practitioners, except for providing references for reasonableness checking.

Proceeding with sources that provide point estimate, we find for instance Becker, Siduh et al. (2009). These authors apply in a simulation study values of $p=0.01,0.02$ or 0.025 corresponding to three different scenarios, and a value of $q=0.4$ for all three scenarios. $M$ is assumed to be a value of $70 \%$ or $90 \%$ percent of the light-vehicle market volume of one year. However, the justifications for these quantifications seem weak at least; they just rely on the interval of values found, for a series of 
technologies, referring to (Mahajan et al., 2004)2. Other authoritative sources are exemplified in Gross (2008) who assumes the Bass parameter values $p=0.01$ and $q=0.1$. In direct email-communications, the author states that he relied on suggestions by Bass (2004) und Schneider (2002) to select these values: The first reference (Bass, 2004) is fairly general, while the second one (Schneider, 2002) does not appear accessible to the research community. Other authors (Davidson, Cross-Call et al. 2013) select p and q values "based on established values" but eventually refer to Becker, Siduh et al. (2009); the market potential $M$ is assumed equal to the number of households in the studied area multiplied by " $0.03,0.25$, and 0.7 in the low, medium, and high growth scenarios". All in all, These literature sources provide only a limited contribution for practitioners looking for reliable Bass diffusion parameters. Additionally, the analysed literature does not provide strong support for its assumption: quoted sources appear evanescent or very general with ,additionally, some tunneling effect when an author quotes an author who quotes an author whose paper is not available. It may then be that secondary sources of data may not be helpful for the potential users of the Bass approach. Observing that parameter values based on authoritative sources provide limited help; this argues in favour of own ad hoc estimates of Bass $p$ and q parameters.

\subsection{Ad hoc estimates in the litterature}

Sources that perform proper estimates can be distinguished based on whether they went through a review process or not. While contemporary science puts a high premium on "reviewed" papers, we believe that, especially in the Bass research area, unreviewed works deserve attention ${ }^{3}$.

Unreviewed works include for instance the estimation by Mac Manus and Senter on HEV annual sale volumes in the U.S. between 1999 and 2008 (MCManus and Senter 2009). Based on their data set and an assumption of a 1.9 million vehicles' market potential, the authors estimate the Bass coefficients pair 0.0026 and 0.709. Additionally, the authors provide other estimates for a generalised Bass model that includes the fuel price as an additional explaining variable. Additional to Mac Manus and Senter, a number of estimates are available in Master Theses that we detail in footnote ${ }^{4}$.

\footnotetext{
2 The reference section of the cited paper (Becker, Siduh et al. 2009, p.31) does not provide information about this entry. Even after making additional research, it does not appear possible to provide accurate information on this source.

${ }^{3}$ They testimony on how Bass models are used in real world applications. In the context of Electric Vehicles where time series of sales data are currently available only for a few years, important information could be present in unreviewed texts.

${ }^{4}$ We posit that Master theses (which could be considered as reviewed or not reviewed) can provide insights in the implementation of Bass models in applied studies. Master theses reflect the ability of an educational system to impart knowledge to prospective users of the respective method. We found the following sources:

Shoemaker (2012) analyses the sales of 585 models of passenger vehicles and utility vehicles between Jan. 1997 and Aug. 2011 on the U.S. market. He finds, that Alternative Fuel Vehicles (AFVs) have already peaked during the estimation period. This corresponds to the observed diffusion pattern at that time where sales exhibited a decrease after peaking in 2007. Under these circumstances, it could be claimed that the model estimate performs well, since the available data at that time described a large part of the product history. But in practitioners view, the contention that AFV have already experienced their peak could be not convincing (although conform to the episode observed in the timeframe considered by Shoemaker). Additionally, Shoemaker performs an out of sample forecast test, that provides moderate adherence to the out of sample observations. This is one of the few cases where the forecast performance of Bass models is evaluated in the literature and these results provide a reason to consider Bass driven results with additional attention.

Other non referred ad hoc estimates relate to an application to a "Beijing EV recharging simulation" proposed by Li, G. (nd). Power Forecasting for Plug-in Electric Vehicles with Statistic Simulations. The author estimates Bass parameters for sales volumes. However, the applied method is not thoroughly described and remains unclear. Li obscurely refers to
} 
Interestingly, most of the unreviewed papers we found relate to studies about the energy sector. We interpret this as a signal about the attractiveness of the Bass model for non-economists, which is due to its good face value. In the next paragraphs, it is considered whether this situation changes if reviewed papers are now considered.

Starting from products that only partly relate to new automotive solutions, Steffens (2003) suggests an extended Bass model by considering multiple units ownership of automobiles in Australia (19661996). The reported $p$ and $q$ values for the first car purchase models are $p=0.0076$ and $q=0.090$ (Steffens 2003), with $\theta$ (with his notations, proportion of the population that can adopt the innovation) equal to 0.914. The limitation of this estimate, for other purposes, is that they relate to market conditions (time framework, location) that cannot easily be transferred to other markets.

Other authors estimate parameters for one market to apply them for estimations for another market. This can relate to technologies (for instance coefficients estimated from Hybrid sale volumes are applied to forecast the market diffusion of Battery Electric Vehicles), but also geographically (from one country to another). This second situation is illustrated by Park et al (2011) who estimate model parameters p, q, m for Korea based on HEV sales in Japan between 1997 and 2006. Subsequently, they "convert" the estimated imitation factor to the Korean context by incorporating results from a comparison of imitation parameters across several Pacific Rim countries (including Japan and Korea) for previously launched products (based on Takada and Jain 1991). In their study, the innovation factor remains unchanged, because in the author's words, "the estimated value for the imitation factor has to be adjusted because the innovation factor reflects the characteristics of the product and/or technology itself, but the imitation factor reflects not only the product or technology characteristics but also customer characteristics (Bass, 1969)“" They obtain ( $p$; q) values equal to $(0.0037 ; 0.3454$ ) and a potential of 10.2 million vehicles. A generalised Bass model is also calibrated using price data relating to the relative price of "Prius" and its Internal Combustion Engine (ICE) equivalent car "Corolla", from 1997 to 2006. Other authors use numbers of new EV car registrations in Norway (Jan. 2003 until June 2013) and implement them in a calibrated model for Denmark (Jensen, Cherchi et al. 2014). This choice relates to the fact that EVs are still too scarce in Denmark while they are more abundant in Norway (see in this issue Figenbaum et al.). They obtain the pair of values $(0.002 ; 0.23)$ while the assumed market potential results from the application of a Discrete Choice Model (a procedure also implemented in Massiani(forthcoming)). However, a critical point could be, that if EVs are more diffused in Norway than in Denmark, then (unless one can establish that the differences in market development are only due to difference in supply) there can be something different in the demand in one country compared with the other. This difference could

a parsimonious description of a "statistic model of EV's in US from 1999 to 2008". Assuming an exogenous potential of 1.9 million sales of EV's, the author obtains the values $p=0.0000365$ and $q=0.447$.

A study by Cordill is based on sale volumes for various Hybrid models between 2000 and 2010 in the U.S., and a forecast of the Plug-in Hybrid Electric Vehicle diffusion is provided. Cordill, A. (2012). Development of a diffusion model to study the greater PEV market. A Thesis Presented to The Graduate Faculty of The University of Akron In Partial Fulfillment of the Requirements for the Degree Master of Science.

Cordill (2012) reports the following Bass parameter values:

$\begin{array}{llllll}\text { Model } & \begin{array}{l}\text { Potential } \\ \text { (Vehicles) }\end{array} & \mathrm{P} & \mathrm{q} & \mathrm{R}^{2} & \mathrm{p} \text {-value } \\ \text { Toyota Prius } & 2875826 & 0.001645368 & 1.455182 & 0.962873 & 0.001 \\ \text { Civic Hybrid } & 3685991 & 0.003437559 & 0.631287 & 0.956147 & 0.001 \\ \text { Ford Escape } & 368377 & 0.03673027 & 0.432231 & 0.999401 & 0.001\end{array}$

${ }^{5}$ Consultation of the original Bass paper does not provide, to our view, strong support to this statement. 
make it illegitimate to transfer parameters. Concerning the geographical issue, as well as to the technology transfer issue, we suggest to undertake further research activities about the performance of Bass-models relying on transferred parameter values.

Finally, in some studies, parameters are calibrated on data from the same markets than the ones of application. So the researcher was in the fortunate position to have sale data at hand for the market for which his research was conducted. One of these contributions was made by Lamberson (2008) on Hybrid Electric Vehicles. Lamberson's final aim was to forecast the diffusion of Hybrid Electric Vehicles in the USA based on monthly vehicle registrations from Feb. 2001 to Oct. 2007 (Lamberson 2008). Parameters of a Bass model and a Gompertz model were estimated by the method of non-linear least squares. Table 1 provides the results together with a conversion to approximated annualised parameters values for comparison purposes.

Table 1 - Coefficient values for a Bass and a Gompertz diffusion model (monthly data and annual approximation, Lamberson 2008)

\begin{tabular}{|c|c|c|c|}
\hline \multirow[t]{2}{*}{ Bass } & Innovation coefficient $\mathrm{p}$ & Imitation coefficient q & $\begin{array}{l}\text { Predicted total market } \\
\text { potential M }\end{array}$ \\
\hline & $\begin{array}{l}0.0000515 \text { (monthly) } \\
0.000618 \text { (approx. annual) }\end{array}$ & $\begin{array}{l}0.0728 \text { (monthly) } \\
0.8736 \text { (approx. a.) }\end{array}$ & $\begin{array}{l}1600000 \text { (monthly) } \\
19200000 \text { (approx. a.) }\end{array}$ \\
\hline \multirow[t]{2}{*}{ Gompertz } & Coefficient $\mathrm{a}$ & Coefficient b & Predicted total market $M$ \\
\hline & 11.2 (monthly) & 0.0118 (monthly) & 25700000 (monthly) \\
\hline
\end{tabular}

Lamberson supports a low innovation coefficient. This result converges with a particularly detailed study made by Cao (2004). Cao provides estimates for sales of Alternative Fuel Vehicles on the Californian market. He made two general assumptions to provide guidance to the interpretation of his results:

(1) "We relaxed one major assumption underlying the basic first-purchase Bass model - we assumed that the market potentials of AFVs [Alternative Fuel Vehicles] do not keep constant but vary as explanatory variables change." (Cao 2004, p. 58).

(2) "We assumed that the market potential of HEVs [Hybrid Electric Vehicles] is around 10\% of total car and truck registrations in 2000." (Cao 2004, p. 68). Cao derives the $10 \%$ assumption from an EIA scenario, in which 19 million Hybrid Electric Vehicles sales between 2001 and 2025 are compared to 220 million vehicles registered in 2002 . So $10 \%$ roughly equates to the share of the current registered fleet compared to total sales in the period 2001-2015 (see p.68). ${ }^{6}$ In subsequent years, the potential is supposed to vary as a function of awareness about the existence of HEV and (lagged) fuel price. In other words, in this model the market potential is supposed to vary at each time step, starting from a $10 \%$ of total registrations, as a function of "awareness" and lagged fuel price.

Cao's estimates are shown in Table 2 below, where results for "Hybrid" refer to model 2 which Cao has chosen as his "final best model".

\footnotetext{
${ }^{6}$ Cao 2004 does not precisely provide reasons for this choice.
} 
Table 2: Bass coefficient values estimated by Cao (2004) for innovative automotive technologies

\begin{tabular}{llll}
\hline & Innovation coefficient & Imitation coefficient & Predicted total market potential \\
& $\mathrm{p}$ & $\mathrm{Q}$ & $\mathrm{M}$ \\
\hline Bioethanol (p.66) & 0.00441 & 0.491 & 245971 \\
CNG (p.58) & 0.021 & 0.265 & 100371 \\
& & 0.4788 & $\begin{array}{l}\text { Exogenous assumption: 10\% of } \\
\text { total registered cars in 2000 }\end{array}$ \\
\hline
\end{tabular}

These values are fairly untypical compared with values cited in the literature for other products. As noted by $\mathrm{Cao}$, the estimated innovation coefficient varies strongly when the initial market diffusion assumption changes. We observe that the coefficient values estimated by Cao imply a very weak innovation for hybrids and a strong imitation effect. This will typically result in a diffusion curve that will have a lengthy start-up phase and a steep increase of diffusion in a second phase.

It could be hypothesised that the very low $\mathrm{p}$ value for Hybrid, results from the shortness of the time series available at that time. The author (Cao 2004, p. 68) reports: "Honda Insight, the first HEV model in the U.S., was introduced in December 1999. Thus the number of observations on HEV sales is even smaller than that for CNG and E85 [consisting of $85 \%$ ethanol and $15 \%$ fossil fuel] vehicle sales. Currently, our HEV data contain the annual sales for only four consecutive years: 2000-2003." In particular, one could doubt that the diffusion of the Hybrid technology had reached its inflexion point at that time, casting doubt on the whole estimation. On this issue, we report the assessment made by Cao:

"(...) the estimates of these parameters [p;q;M] are sensitive to the number of observations available to the estimation (Mahajan, Muller et al. 1990). Heeler and Hustad (1980) suggested that stable and robust parameter estimates can be obtained only if the data under consideration contain at least ten observations and include the peak of the non-cumulative adoption curve, which is supported by the results of Srinivasan and Mason (1986)."

Cao pursues that waiting to have enough observations may just provide results "too late to use the estimates for forecasting purposes" (Mahajan, Muller et al. 1990 p. 9), making the prediction useless (Hyman 1988). "Caught by this fundamental paradox, most operationally useful (as opposed to post-hoc diagnostic) diffusion models are calibrated on relatively little data and hence are not necessarily stable. However, this is a virtually inescapable feature of this modeling approach."(Cao 2004)

\subsection{Summary of available estimates}

In Table 3, we provide a summary of the main results about Bass coefficients for new propulsion technologies which we found in the literature. As these elements suggest, there is a wide discrepancy among $p$ and $q$ values for modeling the market diffusion. A prospective user of the Bass diffusion model would probably be in difficulty when looking for evidence based values of the coefficients.

The question that arises then is whether we get better insights about plausible $p$ and $q$ values by estimating $\mathrm{p}$ and $\mathrm{q}$ from observed market sales. In the next section, we present our own estimations based on data about the real diffusion of various alternative propulsion technologies in Germany. 
Table 3 - available literature estimates for $\mathrm{p}$ and q parameters

\begin{tabular}{|c|c|c|c|c|}
\hline $\begin{array}{l}\text { Source } \\
\text { Technology }\end{array}$ & Method & $\begin{array}{l}\text { Innovation } \\
\text { coefficient } \\
\text { P }\end{array}$ & $\begin{array}{l}\text { Imitation } \\
\text { coefficient } \\
\mathrm{q}\end{array}$ & Market Potential \\
\hline $\begin{array}{l}\text { Becker, Sidhu et al. (2009) } \\
\text { Electric cars }\end{array}$ & Authoritative sources & $\begin{array}{l}0.01 \\
0.02 \\
0.025\end{array}$ & 0.4 & Exogenous: $70 \%$ or $90 \%$ of the light-vehicle market in each year. \\
\hline $\begin{array}{l}\text { Davidson et al. (2013) } \\
\text { Electric cars }\end{array}$ & $\begin{array}{l}\text { Authoritative sources, but eventually } \\
\text { refers to Becker (2009) }\end{array}$ & Idem & Idem & $\begin{array}{l}\text { Exogenous : Number of Household are " } 0.03,0.25 \text {, and } 0.7 \text { in the low, } \\
\text { medium, and high growth scenarios" }\end{array}$ \\
\hline Gross (2008) & Authoritative sources & 0.01 & 0.1 & \\
\hline $\begin{array}{l}\text { Li (nd) } \\
\text { Electric cars }\end{array}$ & $\begin{array}{l}\text { Based on "a statistic model of EVs in US } \\
\text { from } 1999 \text { to } 2008 \text { " }\end{array}$ & 0.0000365 & 0.447 & $\begin{array}{l}\text { Exogenous: "At most half of the vehicles in market can be EVs, the } \\
\text { ultimate market potential is calculated as } 2.5 \text { million". }\end{array}$ \\
\hline $\begin{array}{l}\text { Cordill (2012) } \\
\text { Prius Hybrid } \\
\text { Civic Hybrid } \\
\text { Ford Escape Hybrid }\end{array}$ & Calibration on US market data $2000-2010$ & $\begin{array}{l}0.0016 \\
0.00343 \\
0.036\end{array}$ & $\begin{array}{l}1.45 \\
0.631 \\
0.432\end{array}$ & $\begin{array}{l}\text { Estimated } \\
2.87 \text { million } \\
3.68 \text { million } \\
0.36 \text { million }\end{array}$ \\
\hline $\begin{array}{l}\text { Steffens (2003) } \\
\text { - Conventional cars }\end{array}$ & $\begin{array}{l}\text { First car purchase (not specifically AFV) in } \\
\text { Australia 1966-1996 }\end{array}$ & 0.0076 & 0.0905 & $\begin{array}{l}\text { Exogenous: } 91 \% \text { of the population would finally purchase the } \\
\text { technology. }\end{array}$ \\
\hline $\begin{array}{l}\text { Shoemaker }(2012)^{*} \\
\text { Passenger vehicles } \\
\text { Utility vehicles }\end{array}$ & $\begin{array}{l}\text { Calibration on AFV monthly sales in the } \\
\text { US Dec } 1995 \text { (oct } 2004 \text { for utility AFV) dec } \\
2011 \text { in the US }\end{array}$ & $\begin{array}{l}0.0912 \\
0.008124\end{array}$ & $\begin{array}{l}0.4692 \\
0.4632\end{array}$ & $\begin{array}{l}\text { Estimated } \\
436000 \\
2300000\end{array}$ \\
\hline $\begin{array}{l}\text { Lamberson }(2008)^{*} \\
\text { HEV }\end{array}$ & $\begin{array}{l}\text { Calibration on US monthly sales (Feb. } \\
2001 \text { - Oct. 2007) }\end{array}$ & 0.000618 & 0.8736 & $\begin{array}{l}\text { Estimated } \\
1.6 \text { million veh. }\end{array}$ \\
\hline $\begin{array}{l}\text { Park et al (2011) } \\
\text { HEV }\end{array}$ & $\begin{array}{l}\text { HEV sales in Japan }(1997-2006) \\
\text { parameterized to Korea }\end{array}$ & 0.0037 & 0.3454 & 10,2 million veh. \\
\hline $\begin{array}{l}\text { Jensen et al. (2014) } \\
\text { Electric cars }\end{array}$ & $\begin{array}{l}\text { Norwegian new electric car registration } \\
\text { data from (Jan. } 2003 \text { - Jun. 2013) }\end{array}$ & 0.002 & 0.23 & Exogenous: Result of a Discrete Choice Model \\
\hline $\begin{array}{l}\text { MacManus (2009) } \\
\text { HEV }\end{array}$ & HEV annual Data in the US. (1999-2008) & $\begin{array}{l}0.0026 \\
(0.00124 \text { generalised } \\
\text { Bass })\end{array}$ & $\begin{array}{l}0.709 \\
(0.77922 \\
\text { generalised } \\
\text { bass })\end{array}$ & Estimated : 1.9 million veh. \\
\hline $\begin{array}{l}\text { Cao (2004) } \\
\text { E85 } \\
\text { CNG } \\
\text { Hybrids }\end{array}$ & $\begin{array}{l}\text { Calibration on annual sales in the US } \\
1993-2002\end{array}$ & $\begin{array}{l}0.00441 \\
0.0210 \\
0.000446\end{array}$ & $\begin{array}{l}0.491 \\
0.265 \\
0.4788\end{array}$ & $\begin{array}{l}\text { E85: } 245971 \\
\text { CNG : } 100000 \\
\text { Hybrid: Exogenous. Based on EIA scenario of } 19 \text { million HEV sold until } \\
\text { 2025, subsequently varies in function of HEV awareness and (lagged) } \\
\text { fuel price }\end{array}$ \\
\hline
\end{tabular}

* Monthly coefficients are annualized by multiplication with factor 12 .

${ }^{7}$ Imitation factor modified based on comparison of parameters across several Pacific Rim countries for previously introduced products Takada, H. and D. Jain (1991). "CrossNational Analysis of Diffusion of Consumer Durable Goods in Pacific Rim Countries." Journal of Marketing 55(2): 48-54. 


\section{Estimations based on the German market data}

In this section, we report Bass parameter estimates, based on real market data in Germany. In the next subsection, our available data set is described. Then, the estimation process and results are presented considering two alternative computation methods: In the first, the market potential is endogenous in the estimation. In the second, the market potential is treated as an exogenous variable in the model.

\subsection{Available data}

The estimation is based on time series of sales volumes of a set of innovative technologies. As far as the German car market is concerned, the Kraftfahrtbundesamt (KBA) provides monthly and yearly data on registrations for new cars differentiated by technology.

- Monthly data: New registrations for Liquefied Petroleum Gas (LPG), Compressed Natural Gas (CNG), Electric Vehicles (EV) and Hybrid Electric Vehicles (HEV) are available from Jan. 2009 to Sept. 2014.

- Yearly data: New registrations for LPG, CNG, EV and HEV technologies are available for the period 2005 - 2013 (EV since 2004).

These data constitute the most recent available at the time the estimation is performed. The relatively large quantity of available data may help providing reliable estimates.

Figure 2 - Monthly Passenger Car new registrations in Germany of various alternative propulsion technologies

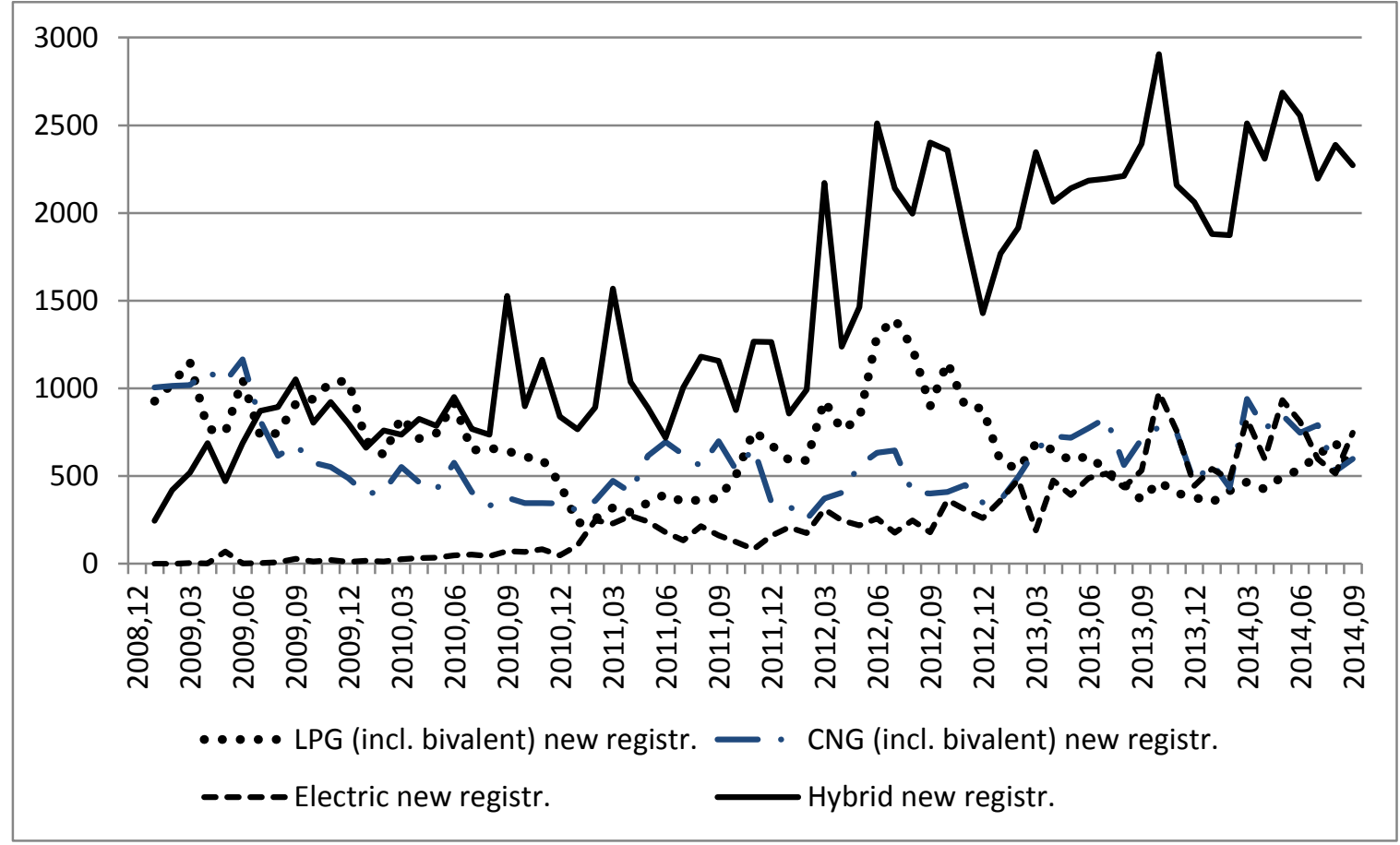

Our elaboration based on : Kraftfahrt-Bundesamt, Flensburg (Germany); monthly data for 31. Dec. 2008 to 30. Sept. 2014 
Figure 3 - Cumulated monthly Passenger Car new registrations in Germany of various alternative propulsion technologies

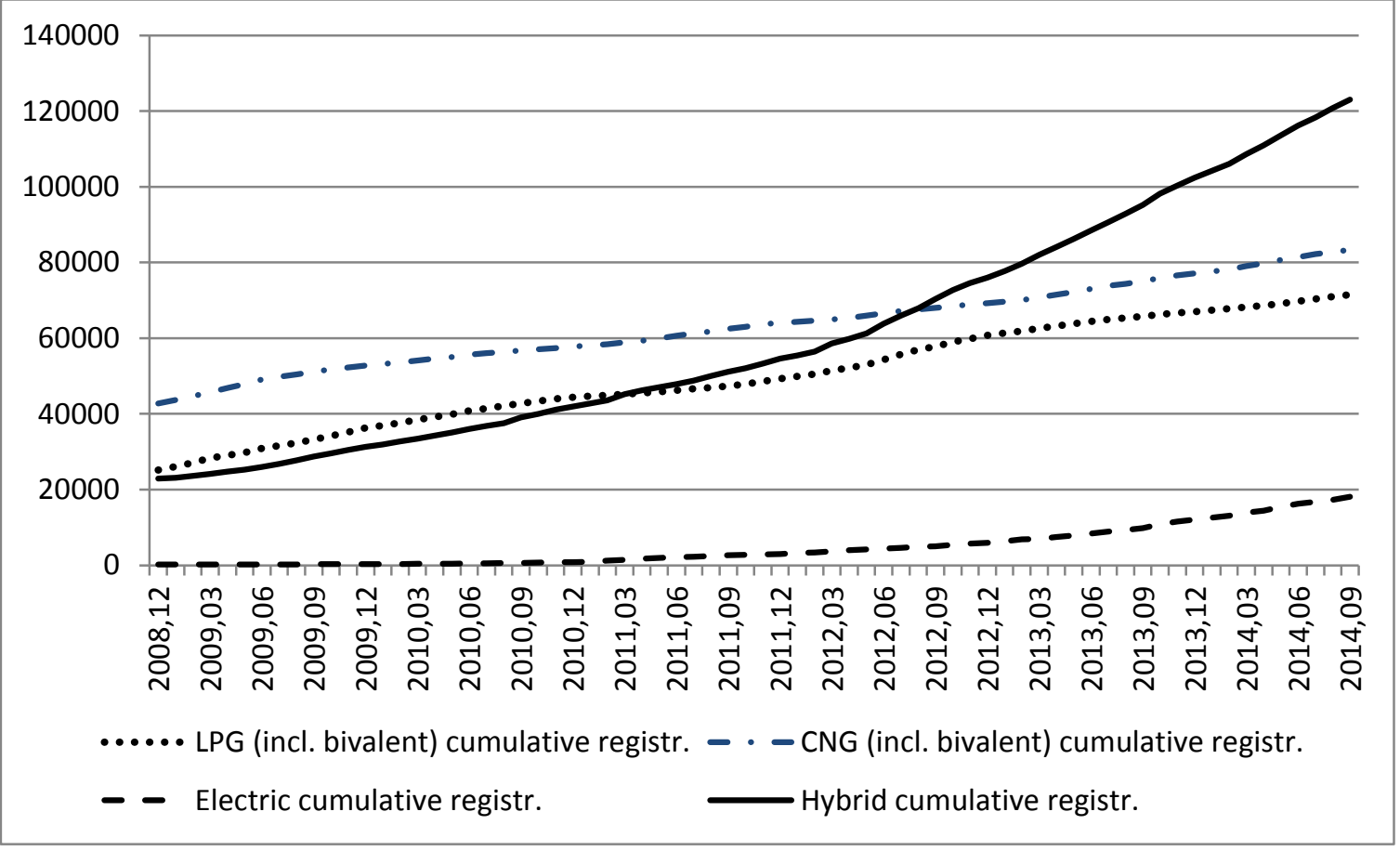

Our elaboration based on : Kraftfahrt-Bundesamt, Flensburg (Germany); monthly data for 31. Dec. 2008 to 30. Sept. 2014, annual data since 2005 (Electric: 2004)

To estimate Bass parameters, the cumulative new vehicles' registrations $N_{t}$ of a given technology at time $t$ have to be used. For this purpose, an estimate of the stock of vehicles on Dec. 31, 2008 is available, based on annual new registrations since 2005 (Electric: since 2004) ${ }^{8}$. The evolution of vehicle registrations and cumulative registration is provided in Figure 2 and Figure 3 respectively. For the estimation of the Bass parameters, these time series of cumulative new registrations $\mathrm{N}_{t}$ are matched with the new registrations $n_{t}$ in the same time frame.

Based on these data, Bass parameter values are estimated using two different fashions, depending on whether the parameter $M$ (the market potential) is endogenous in the estimation (this is the situation commented by Cao (2004)) or whether it is determined exogenously. So, in synthesis, the alternatives are as follows:

1 - Estimation of $p, q$ and $M$ based on the sales of the technology in the first years of diffusion. In this estimation process, the market potential is endogenously estimated together with Bass parameters $p$ and q.

2 - Estimation of $\mathrm{p}$ and $\mathrm{q}$ based on the sales and an exogenous potential $M$, as assumed by the modeler based on other information.

8 It has been checked that monthly and annual data are compatible for the years 2009 to 2013 , so the correspondence of both time series is perfect. 


\subsection{Estimation with model-endogenous market potential}

First, the coefficients $p$ and $q$ are estimated together with the market potential $M$ of a technology. The dependent variable is new registrations $n_{t}$, the explanatory variable is cumulative purchases $N_{t}$ until period $\mathrm{t}$.

Starting with the equation of the Bass diffusion model, it is possible to make some transformations useful for estimation such that:

$$
n_{t}=\frac{d N_{t}}{d t}=p M-p N_{t}+q N_{t}-\frac{q}{M} N_{t}^{2}
$$

And, in a second step:

$$
n_{t}=\frac{d N_{t}}{d t}=p M+(q-p) N_{t}-\frac{q}{M} N_{t}^{2}
$$

Or

$$
n_{t}=\frac{d N_{t}}{d t}=b_{0}-b_{1} N_{t}+b_{2} N_{t}^{2}
$$

with $b_{0}=p M,-b_{1}=q-p$, and $b_{2}=-\frac{q}{M}$.

If a (real) solution to the polynomial equation exists in real numbers, once $b_{0}$ to $b_{2}$ are estimated, the values $\mathrm{p}, \mathrm{q}$ and $\mathrm{m}$ can be calculated. ${ }^{9}$ In our study, the Bass parameters $\mathrm{p}, \mathrm{q}$ and $M$ are calculated from the OLS estimated regression coefficients $b_{0}, b_{1}$ and $b_{2}$ of equation (6), which represents $a$ transformation of the differential equation (3).

Other authors recommend to estimate the Bass coefficients directly from the differential equation (3). Since the differential equation (3) is non-linear, the OLS technique is not applicable. Alternatively, MLE and NLS techniques are proposed to estimate the parameters directly from the differential equation of the diffusion model (Schmittlein and Mahajan 1982, Srinivasan and Mason 1986). This topic is discussed extensively in the literature for instance in Jiang, Bass (2006); Boswijk and Franses (2005); Van den Bulte

${ }^{9} \mathrm{~b}_{0} \mathrm{~b}_{2}=-\mathrm{qp}$ and division by q yields: $\frac{\mathrm{b}_{0} \mathrm{~b}_{2}}{\mathrm{q}}=-\mathrm{p}(1)$. Insert (1) in $-\mathrm{b}_{1}=\mathrm{q}-\mathrm{p}$, yields $-\mathrm{b}_{1}=\mathrm{q}+\frac{\mathrm{b}_{0} \mathrm{~b}_{2}}{\mathrm{q}}$, and addition of $b_{1}$ yields: $q+b_{1}+\frac{b_{0} b_{2}}{q}=0$. Multiplication by $q$ yields: $q^{2}+b_{1} q+b_{0} b_{2}=0$.

This second order polynomial has the following roots : $\mathrm{q}_{1 / 2}=-\frac{\mathrm{b}_{1}}{2} \pm \sqrt{{\frac{\mathrm{b}_{1}{ }^{2}}{4}}^{-}\left(\mathrm{b}_{0} \mathrm{~b}_{2}\right)}$

The index on $q$ indicates that there are possibly up to two solutions in real numbers. Mostly we receive one positive and one negative q value, but only positive values can be meaningful interpreted in the framework of the Bass model. In this case the only positive value is reported. If both solutions are negative, the higher value is reported. A mathematical solution in real numbers exists if the radicand is not negative. If the radicand is negative, $p, q$ and $m$ values cannot be calculated. In this case the term "NA" (Not available) is reported. 
and Stremersch (2004); Venkatesan, Krishnan and Kumar (2004); Lilien et al. (2000); Sultan, Farley and Lehmann (1990); and Van den Bulte and Lilien (1997).

According to Srinivasan and Mason, the model formulation of the NLS approach is as follows:

$$
\mathrm{S}(\mathrm{t})=\mathrm{m}[\mathrm{F}(\mathrm{t})-\mathrm{F}(\mathrm{t}-1)]+\varepsilon(\mathrm{t})
$$

Both techniques (NLS and MLE) provide standard errors of the parameters. However, they have their own limitations. For both approaches, an initial value for each parameter is required to estimate the Bass model and the parameter estimates can be sensitive to the initial values. The model estimation may not converge in some cases, partly due to poor initial values (Judge, Griffiths et al. 1986). Thus OLS estimates obtained from estimation of the transformed equation (6) could be used to provide the initial values for these parameters (cf. Srinivasan and Mason 1986). Using different initial values is also highly recommended in practice (Putsis and Srinivasan 2000).

Comparing both techniques to estimate Bass coefficients from the differential equation (3), the NLS approach is seemingly preferred to the MLE in the literature: (Srinivasan and Mason, 1986, p. 178) claim that, Schmittlein and Mahajan consider in their MLE formulation "only sampling errors and ignore all other errors, such as the effects of excluded variables and the misspecification of the probability density function for adoption time", and thus are likely to underestimate the standard errors of these parameters. Mahajan and Sharma compared both estimation techniques empirically and found an overall superiority of the NLS procedure (Mahajan and Sharma 1986). A simulation study by Srinivasan and Mason (1986) demonstrated that the biases in the parameter estimates are small, less than $7 \%$. More recently, Van de Bulte and Lielen (1997) stated that the estimators in the NLS estimation procedure are consistent but not unbiased. Specifically, by examining both empirical and simulation data, they found that NLS tends to underestimate $\mathrm{m}$ and $\mathrm{p}$ and overestimate $\mathrm{q}$ to a much greater extent than stated by Srinivasan and Mason (1986). They pointed out that the magnitude of the bias depends on the amount of noise in the data, the number of observations, and the differences between the cumulative penetration of the last observation and the true saturation penetration. Thus, one possible solution to minimize the bias is to increase the number of data points, which is consistent with the findings of Putsis (1996).

Generally, the superiority of estimating the Bass coefficients directly from the differential equation (3) rather than from its transformation (6) is not established. For this reason, the presented results are based on the OLS estimate of its transformation (equation number (6)). The results are presented in table 4 and 5.

Table 4 - Estimated Bass-parameters for annual registrations

\begin{tabular}{|c|c|c|c|c|c|c|c|c|c|}
\hline \multirow[b]{2}{*}{ Technology } & \multicolumn{6}{|c|}{ Estimated Regression-Coefficients, (adj.) $R^{2}$ and Radicand } & \multicolumn{3}{|c|}{ Bass-Parameters } \\
\hline & bo & b1 & b2 & $\mathbf{R}^{2}$ & adj. $R^{2}$ & Radicand & p & q & M \\
\hline Electric & 53 & 1.249 & $-4.41 \mathrm{E}-05$ & 0.96 & 0.94 & 1.570 & 0.0019 & 1.2513 & 28383 \\
\hline Hybrid & 4795 & 0.131 & 2.17E-06 & 0.96 & 0.94 & $-2.44 \mathrm{E}-02$ & NA & NA & NA \\
\hline LPG & 5885 & 0.294 & $-4.92 \mathrm{E}-06$ & 0.21 & -0.10 & 0.202199 & 0.0779 & 0.3718 & 75566 \\
\hline CNG & 12972 & \begin{tabular}{|l|}
-0.084 \\
\end{tabular} & $-3.19 \mathrm{E}-07$ & 0.68 & 0.55 & 2.36E-02 & 0.1187 & 0.0349 & 109276 \\
\hline
\end{tabular}

Based on : KBA, Annual registrations (2006 - 2013, Electric: 2005 - 2013) and cumulated new registrations since 2005 (Electric: since 2004) in Germany 
Table 5 - Estimated Bass-parameters for monthly registrations

\begin{tabular}{|c|c|c|c|c|c|c|c|c|c|}
\hline \multirow[b]{2}{*}{ Technology } & \multicolumn{2}{|c|}{$\begin{array}{ll}\text { Estimated } & \mathrm{R} \\
\text { Radicand } & \end{array}$} & \multicolumn{3}{|c|}{ Regression-Coefficients, } & $(\operatorname{adj}.) \quad R^{2} \quad$ and & \multicolumn{3}{|c|}{ Bass-Parameters } \\
\hline & b0 & b1 & b2 & $\mathbf{R}^{2}$ & adj. $R^{2}$ & Radicand & $p$ & $q$ & $M$ \\
\hline Electric & 11 & 0.071 & $-1.74 \mathrm{E}-06$ & 0.84 & 0.84 & $5.16 \mathrm{E}-03$ & 0.00027 & 0.07159 & 41236 \\
\hline Hybrid & -463 & 0.045 & $-1.72 \mathrm{E}-07$ & 0.80 & 0.80 & $1.68 \mathrm{E}-03$ & -0.00186 & 0.04281 & 249452 \\
\hline LPG & 1400 & -0.024 & $1.68 \mathrm{E}-07$ & 0.14 & 0.11 & $-3.83 \mathrm{E}-04$ & NA & NA & NA \\
\hline CNG & 5545 & -0.159 & $1.24 \mathrm{E}-06$ & 0.45 & 0.43 & $-2.23 E-03$ & NA & $\mathrm{NA}$ & NA \\
\hline
\end{tabular}

Based on : KBA, Monthly registrations (Jan. 2009 - Sept. 2014) and cumulated new registrations since 2005 (Electric since 2004) in Germany

Available data indicate that there were about 71545 LPG new registrations in 2005 - 2014 and a fleet stock for LPG of 500867 (Jan. 1 $^{\text {st }}, 2014$ ). So the estimated market potentials reported in Table 4 are unrealistic low for the LPG technology. For Electric Vehicles a q-coefficient larger than one is obtained. For Hybrids, there exists no (real) solution for the $p$ and $q$, because the square root of the radicand is negative. The results reported in Table 4 are estimated from annual data. Table 5 provides estimates from monthly data. From estimations of monthly data we get negative radicands for the LPG and CNG technologies, so no valid $\mathrm{p}$ and $\mathrm{q}$ values can be calculated. For Hybrids a negative $\mathrm{p}$ value is calculated. Only for the technology "Electric" we derive plausible $p$ - and q-values but a low estimate for the market potential. Since $\mathrm{p}$ - and $\mathrm{q}$-values are estimated for monthly periods we multiply these values to approximate annual $\mathrm{p}$ and $\mathrm{q}$ values, see Table 6.

Table 6 - Estimated Bass-Parameters for Electric vehicles (endogenous potential estimate)

\begin{tabular}{|l|r|r|r|}
\hline $\begin{array}{l}\text { Frequency of time } \\
\text { series }\end{array}$ & \multicolumn{1}{|c|}{$\mathbf{p}$} & \multicolumn{1}{|c|}{$\mathbf{q}$} \\
\hline Annual data & 0.0019 & 1.2513 & 28383 \\
\hline Monthly data* & 0,00322 & 0,85912 & 41236 \\
\hline
\end{tabular}

* annualised $\mathrm{p}$ and q parameter values (approximated by multiplication of parameter values for monthly data by 12)

So the ad hoc estimated parameters are of limited benefit for practitioners, at least considering the data currently available. In order to further check for the possibility that a particular data configuration may lead to this result, estimations have been applied to another data set relating to sales in Japan and overseas. These other estimates, presented in the appendix lead to a similar conclusion. This pessimistic conclusion echoes certain findings in the literature: Van den Bulte and Lilien (1997 p. 2045) claim that in application of the model, "the estimated population size [meaning market potential $\mathrm{M}]$ is close to the cumulative number of adopters observed in the last time period for which data are available." They also claim that this approach results in an "upward bias in the contagion [imitation] parameter."

This, pessimistic, conclusion could however result from the endogenous approach at stake. The next section proceeds with the other approach, the one relying on the exogenous quantification of the market 
potential $M$, thus focusing on the sole estimate of parameters $p$ and $q$. In such a situation, $M$ is defined a priori, independently of the estimate of $\mathrm{p}$ and $\mathrm{q}$.

\subsection{Estimation with exogenous market potential}

In this section, the market potential $M$ of the Bass-model is fixed exogenously. When calibrating $p$ and $\mathrm{q}$ based on exogenous potential assumptions, much attention should be dedicated to the quantification of the potential $M$; especially the estimate of the Bass $p$ parameter depends on the a priori assumed market potential, see table 7. The quantification of $M$ is not an easy task. This is illustrated by the general lack of solid argumentation on the value chosen for the parameter $M$ that can be observed in the existing literature.

The estimation of Bass parameter values proceeds as follows, starting again from equation (1).

This equation can be rewritten as:

$$
n_{t}=\frac{d N_{t}}{d t}=p X_{t}+q Y_{t}
$$

with $X_{t}=M-N_{t}$ and $Y_{t}=\frac{1}{M} N_{t}\left(M-N_{t}\right)$.

If $\mathrm{M}$ and $N_{t}$ are given, both $\mathrm{X}_{\mathrm{t}}$ and $\mathrm{Y}_{\mathrm{t}}$ can be calculated. This makes it possible to estimate $\mathrm{p}$ and $\mathrm{q}$.

\subsubsection{Model based on monthly data for Electric vehicles, Hybrids, LPG and CNG}

First, estimates are made based on monthly data from KBA on new registrations (Jan. 2009 - Sept. 2014) and cumulative new registrations since 2005 for EV, HEV, LPG and CNG. Additionally, in order to investigate the sensitivity of the $p$ and $q$ estimates to the market potential, various values for market potentials are considered: $M=0.1,0.5,0.7,1,5,10$ and 20 million vehicles. The resulting values of $p$ and q parameters are provided in Table 7 and Errore. L'origine riferimento non è stata trovata. Table 8.

Table 7 - Estimated Bass p values (monthly new registrations) for different assumed market potentials

\begin{tabular}{|l|l|l|l|l|l|l|l|}
\hline Bass-p-values & \multicolumn{2}{l|}{ Market potential in million passenger cars } \\
\hline Technology & 0.1 & 0.5 & 0.7 & 1 & 5 & 10 & 20 \\
\hline Electric & $3.56 \mathrm{E}-04$ & $9.26 \mathrm{E}-05$ & $6.71 \mathrm{E}-05$ & $4.75 \mathrm{E}-05$ & $9.69 \mathrm{E}-06$ & $4.86 \mathrm{E}-06$ & $2.43 \mathrm{E}-06$ \\
Hybrid & $2.86 \mathrm{E}-03$ & $-1.10 \mathrm{E}-04$ & $3.40 \mathrm{E}-05$ & $7.50 \mathrm{E}-05$ & $3.12 \mathrm{E}-05$ & $1.65 \mathrm{E}-05$ & $8.46 \mathrm{E}-06$ \\
LPG & $7.99 \mathrm{E}-03$ & $2.10 \mathrm{E}-03$ & $1.49 \mathrm{E}-03$ & $1.04 \mathrm{E}-03$ & $2.05 \mathrm{E}-04$ & $1.02 \mathrm{E}-04$ & $5.10 \mathrm{E}-05$ \\
CNG & $7.11 \mathrm{E}-04$ & $1.49 \mathrm{E}-03$ & $1.05 \mathrm{E}-03$ & $7.31 \mathrm{E}-04$ & $1.44 \mathrm{E}-04$ & $7.16 \mathrm{E}-05$ & $3.58 \mathrm{E}-05$ \\
\hline
\end{tabular}

Data KBA: Registrations (Jan. 2009 - Sept. 2014) and cumulated new registrations since 2005 (Gasoline, Diesel, Electric since 2004) in Germany 
Table 8 - Estimated Bass q values (monthly new registrations) for different assumed market potentials

\begin{tabular}{|l|l|l|l|l|l|l|l|}
\hline Bass-q-values & \multicolumn{7}{|l|}{ Market potential in million passenger cars } \\
\hline Technology & 0.1 & 0.5 & 0.7 & 1 & 5 & 10 & 20 \\
\hline Electric & 0.055 & 0.048 & 0.047 & 0.047 & 0.046 & 0.046 & 0.046 \\
Hybrid & 0.036 & 0.029 & 0.027 & 0.025 & 0.022 & 0.022 & 0.022 \\
LPG & 0.012 & -0.006 & -0.006 & -0.007 & -0.007 & -0.007 & -0.007 \\
CNG & 0.025 & -0.001 & -0.001 & -0.002 & -0.002 & -0.002 & -0.002 \\
\hline
\end{tabular}

Data KBA: Registrations (Jan. 2009 - Sept. 2014) and cumulated new registrations since 2005 (Gasoline, Diesel, Electric since 2004) in Germany

The results of the estimations are, of course, dependent on the assumed market potential for various technologies. The market potential of 10 million cars is arguably a reasonable estimate for the size of the market potential $M$ for Hybrid Electric Vehicles ${ }^{10}$. The estimated parameters in Table 7 and Table 8 correspond to monthly values, the corresponding annual $\mathrm{p}$ and $\mathrm{q}$ values are approximated by multiplication with the factor 12 . Accordingly, an annual $p$-value of 0.0002 and an annual q-value of 0.26 constitute the best available estimates for hybrids' diffusion.

\subsubsection{Model based on annual data for Electric vehicles, Hybrids, LPG and CNG}

Recalling that KBA data for new propulsion technologies are also available on an annual basis for the period 2005-2013, $\mathrm{p}$ and $\mathrm{q}$ are also fitted on annual sales data. Additionally, to complement these models, GDP growth rates and a dummy variable for car scrappage scheme ("Abwrackprämie") were tested as explanatory variables in the models. Since these variables were not found significant or did not have additional explanatory power, they were discarded.

Table 9 - Estimated Bass p values (annual new registrations) for different assumed market potentials

\begin{tabular}{|l|r|r|r|r|r|r|r|}
\hline & \multicolumn{7}{|l|}{ Market potential in million passenger cars } \\
\hline & 0.1 & 0.5 & 0.7 & 1 & 5 & 10 & 20 \\
\hline Electric & $1.11 \mathrm{E}-03$ & $2.53 \mathrm{E}-04$ & $1.82 \mathrm{E}-04$ & $1.28 \mathrm{E}-04$ & $2.60 \mathrm{E}-05$ & $1.30 \mathrm{E}-05$ & $6.50 \mathrm{E}-06$ \\
Hybrid & $-2.15 \mathrm{E}-02$ & $4.37 \mathrm{E}-03$ & $3.38 \mathrm{E}-03$ & $2.49 \mathrm{E}-03$ & $5.42 \mathrm{E}-04$ & $2.74 \mathrm{E}-04$ & $1.37 \mathrm{E}-04$ \\
LPG & $6.94 \mathrm{E}-02$ & $1.61 \mathrm{E}-02$ & $1.15 \mathrm{E}-02$ & $8.08 \mathrm{E}-03$ & $1.62 \mathrm{E}-03$ & $8.12 \mathrm{E}-04$ & $4.06 \mathrm{E}-04$ \\
CNG & $1.26 \mathrm{E}-01$ & $2.70 \mathrm{E}-02$ & $1.92 \mathrm{E}-02$ & $1.34 \mathrm{E}-02$ & $2.67 \mathrm{E}-03$ & $1.33 \mathrm{E}-03$ & $6.66 \mathrm{E}-04$ \\
\hline
\end{tabular}

Data KBA: registrations (2006 - 2013, Electric: 2005 - 2013) and cumulated new registrations since 2005 (Electric: since 2004) for different assumed market potentials

\footnotetext{
${ }^{10}$ This estimate is derived from a metaanalysis based on a Synthetic Utility Function that produces forecasts of market shares for competing propulsion technologies, see Massiani, J. (2012). Using Stated Preferences to forecast alternative fuel vehicles market diffusion. Italian Journal of Regional Sciences. 11: 93-122. This latest model suggests an average market share of hybrid cars over the next ten years of $25 \%$ (before diffusion is accounted for). Applying this $25 \%$ estimate to the stock of cars in Germany of around 40 million suggests a market potential of 10 million cars.
} 
Table 10 - Estimated Bass q values (annual new registrations) for different assumed market potentials

\begin{tabular}{|l|r|r|r|r|r|r|r|}
\hline & \multicolumn{7}{|l|}{ Market potential in million passenger cars } \\
\hline & 0.1 & 0.5 & 0.7 & 1 & 5 & 10 & 20 \\
\hline Electric & 1.061 & 1.010 & 1.007 & 1.004 & 1.000 & 0.999 & 0.999 \\
Hybrid & 0.789 & 0.357 & 0.339 & 0.327 & 0.305 & 0.302 & 0.301 \\
LPG & 0.204 & 0.024 & 0.018 & 0.013 & 0.005 & 0.004 & 0.003 \\
CNG & 0.071 & -0.097 & -0.101 & -0.103 & -0.108 & -0.108 & -0.109 \\
\hline
\end{tabular}

Data KBA: Annual registrations in Germany (2006 - 2013, Electric: 2005 - 2013) and cumulated new registrations since 2005 (Electric: since 2004)

These results provide estimates of the correct sign for Electric Vehicles and LPGs, and for realistic market potential numbers also for Hybrids. For CNG we do not get realistic, i.e. positive q coefficients for market potentials between 0.5 and 20 million cars. The q values close to one for $\mathrm{EV}$ are not reasonable. For LPG, Bass q parameter values decline with a growing market potential and are unrealistically low. Control variables for GDP in levels and returns, nominal and real were tested but are not significant. Altogether, given an exogenous market potential, only for Hybrids we get plausible Bass estimates from monthly as well as annual time series. For Electric Vehicles we get from monthly time series results which are consistent with the Bass approach. The helpfulness of these estimates need however to be assessed taking in consideration the other results obtained.

Additionally, it becomes apparent that the Bass $p$ value is sensitive to the assumed market potential. For a wide range of hypothesised market potentials $\mathrm{m}$ between 0.5 and 20 million passenger cars, we find an inverse relationship between the assumed $m$ and the estimated $p$ value. Precisely, a doubling of $m$ results in a bisection of the Bass $p$ value. This high sensitivity makes it very difficult to draw conclusions for the actual value of $p$. Interestingly, the estimated Bass q parameter values vary only marginally for this range of market potentials. Since we believe that for car technologies the actual market potential should fall in this range of assumed market potentials or could just be higher, we recommend to derive the Bass q parameter value from an estimation with exogenous market potential. If a Bass q value is estimated which is not realistic, this could be that the diffusion process may not follow Bass or that the time series available for estimation purposes is too short and does not contain enough information. So the estimate (with exogenous market potential) of the Bass q value could serve as a first step to test if Bass is appropriate to fit the diffusion process. If the researcher wants to apply Bass despite an unreliable $q$ value from ad-hoc estimation, she could transfer Bass values estimated for other markets (published in the literature or from own ad-hoc estimations). If the ad-hoc estimated Bass q value is realistic, the researcher could still be doubtful concerning the sensible $p$ value. Since our results reveal that there exists no panacea to solve this problem, we suggest to follow different strategies: As far as the researcher is confident concerning in her selected exogenous market potential $M$, the Bass $p$ parameter can be determined by $M$ and $\mathrm{q}$. Otherwise, if the researcher can rather be confident in a range of plausible market values, perhaps the researcher could find a solution in a simultaneous estimation of $M$ and $p$ given q. Following this strategy, the Bass approach with model-endogenous $M, p$ and $q$ becomes obsolete.

\section{Conclusions}

During a research project about the evaluation of policies to promote the market diffusion of Electric Vehicles in Germany, the potential for the use of the Bass diffusion model has been investigated. 
During this research, additional to an interrogation on the estimation of the market potential, an investigation on the value to be used for $\mathrm{p}$ and $\mathrm{q}$ parameters has been performed. This investigation has led us to consider values obtained through ad hoc estimates and values proposed in the literature. The main quantitative evidences collected during this investigation are illustrated in Table 11 and figure 4.

Table 11 - Comparison of Bass parameters estimates

\begin{tabular}{|c|c|c|}
\hline Source & $\begin{array}{c}\text { Innovation coefficient } \\
\mathbf{p}\end{array}$ & $\begin{array}{l}\text { Imitation coefficient } \\
\mathrm{q}\end{array}$ \\
\hline \multicolumn{3}{|l|}{1 - Literature estimates } \\
\hline Becker, Sidhu et al. (2009) & $0.01,0.02$ or 0.025 & 0.4 \\
\hline Davidson et al. (2013) & Idem & Idem \\
\hline Gross (2008) & 0.01 & 0.1 \\
\hline $\mathrm{Li}(\mathrm{nd})$ & 0.0000365 & 0.447 \\
\hline Cordill (2012) Prius & 0.0016 & 1.45 \\
\hline Hybrid Civic & 0.00343 & 0.631 \\
\hline Ford Escape & 0.036 & 0.432 \\
\hline Steffens (2003) : Conventional cars & 0.0076 & 0.0905 \\
\hline \multirow[t]{2}{*}{ Schoemaker $(2012)^{*}$} & 0.0912 (pass. veh) & 0.4692 (pass.veh) \\
\hline & 0.008124 (utility veh) & 0.4632 (utility veh.) \\
\hline Lamberson (2008) HEV* & 0.000618 & 0.8736 \\
\hline Park et al (2011) & 0.0037 & 0.3454 \\
\hline Jensen et al. (2014) & 0.002 & 0.23 \\
\hline MacManus (2009) & 0.0026 & 0.709 \\
\hline Cao (2004) - Hybrids & 0.000446 & 0.4788 \\
\hline \multicolumn{3}{|l|}{2 - Own estimates } \\
\hline endogenous potential - KBA yearly data & 0.0019 & 1.2513 \\
\hline endogenous potential - KBA monthly data* & 0.00322 & 0.8591 \\
\hline \multirow{2}{*}{$\begin{array}{l}\text { exogenous potential }(=10 \mathrm{mln})-\mathrm{KBA} \\
\text { annual data }\end{array}$} & 0.000013 & 0.999 \\
\hline & 0.000274 (Hybrids) & 0.302 (Hybrids) \\
\hline \multirow{2}{*}{$\begin{array}{l}\text { exogenous potential }(=10 \mathrm{mln})-\mathrm{KBA} \\
\text { monthly data* }\end{array}$} & 0.00005832 & 0.552 \\
\hline & 0.000198 (Hybrids) & 0.264 (Hybrids) \\
\hline Toyota Hybrid, worldwide & 0.0007 & 0.2422 \\
\hline Toyota Hybrid, Europe & 0.0008 & 0.2318 \\
\hline
\end{tabular}

Note: * Parameters estimated based on monthly data were annualised by multiplication with factor 12 


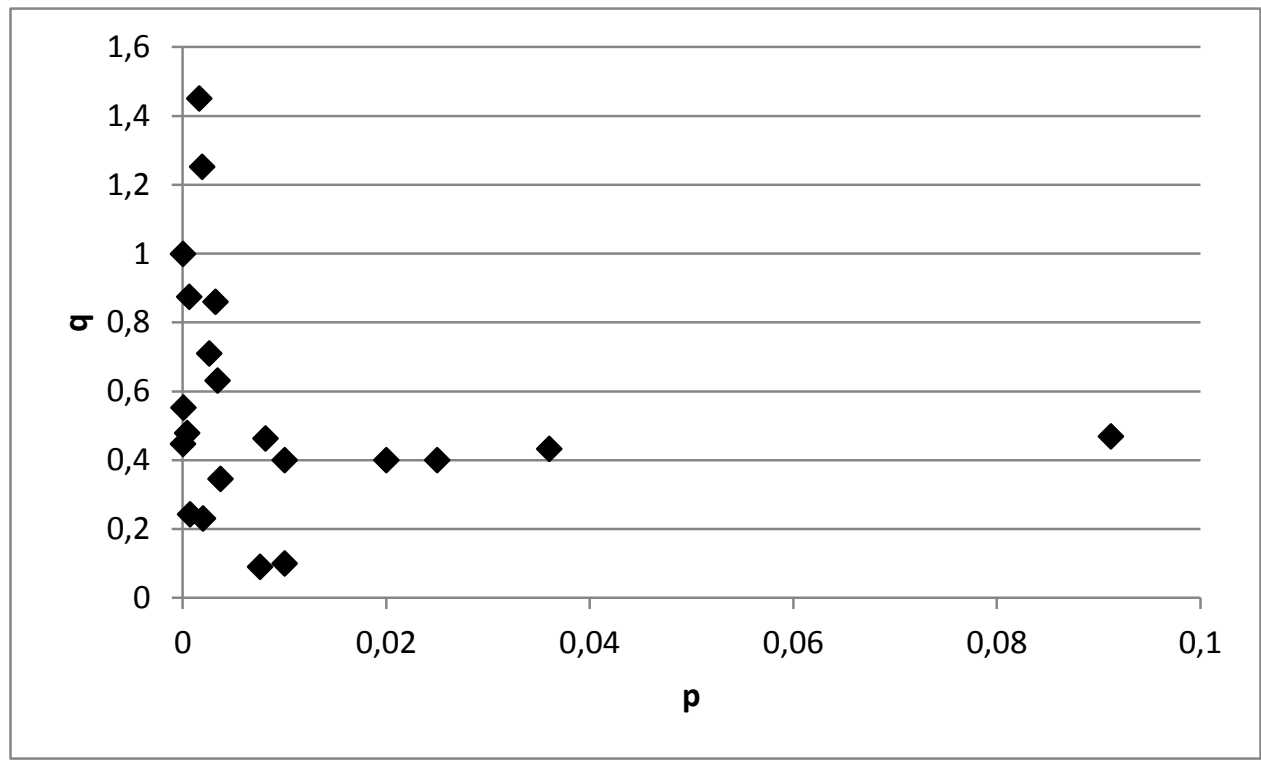

Figure 4 - scatter of available $p$ and $q$ values

This comparison makes a few findings apparent:

First, there appears a very large discrepancy among available estimates. There is a large variety among literature estimates and there is also a large variety (and sometimes inconsistency if the results have the wrong sign) among ad hoc estimates. Concerning the ad-hoc estimates it apprears that the Bass $\mathrm{p}$ parameter is not stable and sensitive towards the assumed market potential $M$. If there is an uncertainty concerning the hypothesised $M$, our estimation results show that different $p$ values could be plausible which differ in factors of up to ten or even 100. In this difficult environment we propose to follow different ways, for example to try a two-step approach: In a first step the Bass q value could be estimated from the Bass-model with exogenous determined market potential. In a second step the researcher has several options to estimate the Bass $p$ value given $M$ and $q$ or - if she is insecure about the exogenously determined $M$ - she can simultaneously estimate $M$ and $p$ given $q$. Additionally, the researcher can take Bass q values or all Bass parameters proposed in the literature.

Second, the hypothesised market potential (when exogenous) is found to be highly influential for the $p$ parameter values, while the q value is only marginally affected by this value. Our results show that a decisive element for the simulation of the market diffusion is constituted by the quantification of the market potential, which in most practical cases (considering the problems arising when the potential is endogenous in the estimation), will be assumed prior to application of the Bass model.

Third, one can observe that the two available sources (Cao and Lamberson) that, considering the investigated product, most closely match the German electric mobility market, exhibit anomalous low values for the $\mathrm{p}$ coefficient. Prospective users of the Bass approach should pay special attention when deciding to transfer such values in their own models.

More generally, the strong pattern of dispersion of the reported parameter values suggests that the use of any of the estimated parameters (or any aggregation or averaging thereof) would require attention. The various estimates provide results that sometimes differ by several orders of magnitude, 
and the theory does not indicate an ultimate selection criterion among such different results. Until these interrogations have not received a convincing answer, there generally appears a warning to the prospective users of Bass parameters for the electric vehicles' diffusion.

Acknowledgment: We thank our former colleagues from ESMT Berlin Jens Weinmann, Giselmar Hemmert and Jörg Radeke for valuable discussions. 


\section{Appendix : Estimates based on Toyota Hybrid annual sales in Japan and overseas}

An estimation of Bass coefficients is performed using data for sales of Toyota Hybrid vehicles (incl. plug-in hybrid vehicles) in Japan, North-America, Europe and global for the years 1997 until 2013.

Figure 5 Cumulative Toyota sales volumes (in 1000 Hybrids) 1997 - 2013

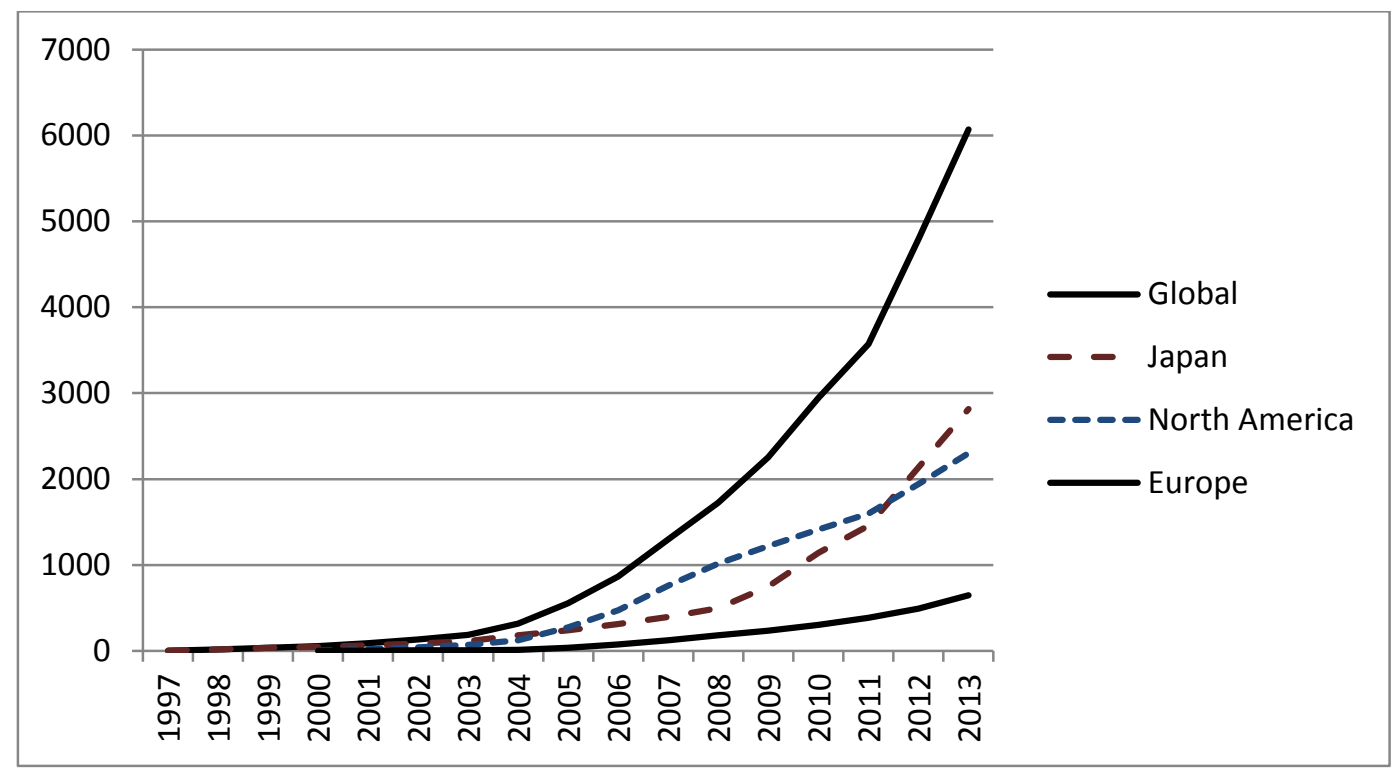

Source:http://corporatenews.pressroom.toyota.com/releases/worldwide+toyota+hybrid+sales+top+6+million.h tm, call date: Nov. 3, 2014

From these time series Bass $p, q$ and $M$ parameter values are estimated:

Table 12 - Estimated regression coefficients and Bass' p, q and M parameters for Toyota Hybrids

\begin{tabular}{|l|r|r|r|r|r|r|r|r|r|}
\hline & \multicolumn{3}{|c|}{ Estimated Regression-Coefficients. (adj.) $\mathbf{R}^{2}$ and } & \multicolumn{4}{c|}{ Radicand } & \multicolumn{1}{c|}{ Bass-Parameters } \\
\hline Sales in... & b0 & b1 & b2 & $\mathbf{R}^{2}$ & $\begin{array}{c}\text { adj. } \\
\mathbf{R}^{2}\end{array}$ & Radicand & p & q & M \\
\hline Global & 31840 & 0.241 & $-5.22 \mathrm{E}-09$ & 0.97 & 0.96 & 0.0590 & 0.0007 & 0.2422 & 46365287 \\
Japan & -7719 & 0.329 & $-2.51 \mathrm{E}-08$ & 0.96 & 0.96 & 0.1072 & -0.0006 & 0.3280 & 13049654 \\
North America & 35228 & 0.234 & $-4.87 \mathrm{E}-08$ & 0.79 & 0.75 & 0.0618 & 0.0071 & 0.2416 & 4962585 \\
Europe & 6887 & 0.231 & $-2.64 \mathrm{E}-08$ & 0.96 & 0.96 & 0.0541 & 0.0008 & 0.2318 & 8772998 \\
\hline
\end{tabular}

Our results provide an unconvincing negative $p$ parameter for Japan. The results for worldwide market and European market are very similar, when considering the $\mathrm{p}$ and $\mathrm{q}$ parameters, and appear in a reasonable range. It is however possible to object that a model calibrated on worldwide or continental data is of limited relevance for application in a single country, a situation that may often present itself to the analyst. 


\section{Bibliography}

Bass, F. M. (1969). "A New Product Growth for Model Consumer Durables." Management Science 15(5): 215-227.

Bass, F. M. (2004). "Comments on 'A New Product Growth for Model Consumer Durables': The Bass Model." Management Science Vol. 50(No. 12): 1833-1840.

Bass, F. M., T. V. Krishnan and D. C. Jain (1994). "Why the Bass Model Fits without Decision Variables." Marketing Science 13(3): 203-223.

Becker, T. A., I. Siduh and B. Tenderich (2009). Electric Vehicles in the United States A New Model with Forecasts to 2030. Berkeley, University of California.

Boswijk, H. P. and P. H. Franses (2005). "On the econometrics of the bass diffusion model." Journal of Business and Economic Statistics 23(3): 255-268.

Cao, X. (2004). "The Future Demand for Alternative Fuel Passenger Vehicles: A Diffusion of Innovation Approach."

Chandrasekaran, D. and G. J. Tellis (2007). A Critical Review of Marketing Research on Diffusion of New Products. Review of Marketing Research. N. K. Malhotra. 3: 39-80.

Cordill, A. (2012). Development of a diffusion model to study the greater PEV market. A Thesis Presented to The Graduate Faculty of The University of Akron In Partial Fulfillment of the Requirements for the Degree Master of Science.

Davidson, M., D. Cross-Call, M. Craig and A. Bharatkumar (2013). Assessing Options for Accommodating Electric Vehicles in Santa Delano Valley. USAEE Case Competition 2013. T. T. a. P. Group: 49.

Gross, U. (2008). Prognose des Absatzmarktes für alternative Antriebe - Modellbildung und Simulation, Universität Karlsruhe (TH): 174.

Heeler, R. M. and T. P. Hustad (1980). "Problems in predicting new product growth for consumer durables." Management Science 26(10): 1007-1020.

Hyman, M. R. (1988). "The timeliness problem in the application of Bass-type new product growth

models to durable sales forecasting." Journal of Business Research 16(l): 31-47.

Jensen, A. F., E. Cherchi, S. L. Mabit and J. d. D. Ortúzar (2014). Predicting The Potential Market For Electric Vehicles. Transportation Research Board.

Jiang, Z., F. M. Bass and P. I. Bass (2006). "Virtual Bass Model and the left-hand data-truncation bias in diffusion of innovation studies." International Journal of Research in Marketing 23(1): 93-106. 
Judge, G. G., W. E. Griffiths, R. C. Hill, H. Lütkepohl and T.-C. Lee (1986). The Theory and Practice of Econometrics, Wiley: 1056.

Lamberson, P. J. (2008). The Diffusion of Hybrid Electric Vehicles. Future Research Directions in Sustainable Mobility and Accessibility. Sustainable Mobility Accessibility Research and Transformation (SMART) at the University of Michigan Center for Advancing Research and Solutions for Society (CARSS).

Lee, D. H., S. Y. Park, J. W. Kim and S. K. Lee (2013). "Analysis on the feedback effect for the diffusion of innovative technologies focusing on the green car." Technological Forecasting and Social Change 80(3): 498-509.

Li, G. (nd). Power Forecasting for Plug-in Electric Vehicles with Statistic Simulations.

Lilien, G. L., A. Rangaswamy and C. Van den Bulte (2000). Diffusion models: Managerial applications and software. New product diffusion models. V. Mahajan, E. Muller and Y. Wind. New York, Kluwer Academic Publishers.

Mahajan, V., E. Muller and F. M. Bass (1990). "New Product Diffusion Models in Marketing: A Review and Directions for Research." The Journal of Marketing 54(1): 1-26.

Mahajan, V. and S. Sharma (1986). "Simple Algebraic Estimation Procedure for Innovation Diffusion Models of New Product Acceptance." Technological Forecasting and Social Change 30(December): 331346.

Massiani, J. (2012). Using Stated Preferences to forecast alternative fuel vehicles market diffusion. Italian Journal of Regional Sciences. 11: 93-122.

Massiani, J. (forthcoming). "Cost-Benefit Analysis of policies for the development of electric vehicles in Germany: methods and results." Transport policy 38: 19-26.

McManus, W. and R. J. Senter (2009). Market Models for Predicting PHEV Adoption and Diffusion. Technical Challenges of Plug-In Hybrid Electric Vehicles and Impacts to the U.S. Power System, Subcontract No. 46827, Task 2c: Final Report.

Park, S. Y., J. W. Kim and D. H. Lee (2011). "Development of a market penetration forecasting model for Hydrogen Fuel Cell Vehicles considering infrastructure and cost reduction effects." Energy Policy 39(6): 3307-3315.

Putsis, W. and V. Srinivasan (2000). Estimation techniques for macro diffusion models. New-Product Diffusion Models. E. M. a. Y. W. in V. Mahajan. London, Kluwer Academic Publishers: 263-291.

Putsis, W. P., Jr. (1996). "Temporal aggregation in diffusion models for first-time purchase: Does choice of frequency matter?" Technological Forecasting and Social Change 51(3): 265-279.

Schmittlein, D. C. and V. Mahajan (1982). "Maximum Likelihood Estimation for an Innovation Diffusion Model of New Product Acceptance,." Marketing 1(winter): 57-78. 
Schneider, M. (2002). Explorative Studie zur Markteinführung von Brennstoffzellenfahrzeugen, Universität Karlsruhe (TH).

Shoemaker, M. H. (2012). A Bass Diffusion Model Analysis: Understanding Alternative Fuel Vehicle Sales, Claremont McKenna College.

Srinivasan, V. and C. H. Mason (1986). "Nonlinear least squares estimation of new product diffusion models." Marketing Science 15(4): 169-178.

Steffens (2003). "A Model of Multiple-Unit Ownership as a Diffusion Process." Technological Forecasting and Social Change 70(9): 901-917.

Sultan, F., J. U. Farley and D. R. Lehmann (1990). "A Meta-Analysis of Applications of Diffusion Models." Journal of Marketing Research 27(1): 70-77.

Takada, H. and D. Jain (1991). "Cross-National Analysis of Diffusion of Consumer Durable Goods in Pacific Rim Countries." Journal of Marketing 55(2): 48-54.

Van den Bulte, C. and G. Lilien (1997). Why Bass model Estimates May Be Biased (and What It Means), The Pennsylvania State University: 7.

Van den Bulte, C. and G. L. Lilien (1997). "Bias and Systematic Change in the Parameter Estimates of Macro-Level Diffusion Models." Marketing Science 16(4): 338-353.

Van Den Bulte, C. and S. Stremersch (2004). "Social contagion and income heterogeneity in new product diffusion: A meta-analytic test." Marketing Science 23(4): 530-544.

Venkatesan, R., T. V. Krishnan and V. Kumar (2004). "Evolutionary Estimation of Macro-Level Diffusion Models Using Genetic Algorithms: An Alternative to Nonlinear Least Squares." Marketing Science 23(3): 451-464. 